\title{
PROFESI
}

PENDIDIKAN DASAR

\section{IDENTIFIKASI PENGETAHUAN DAN KETERAMPILAN PERLINDUNGAN DIRI ANAK DARI PELECEHAN SEKSUAL DI SD MUHAMMADIYAH 1 SURAKARTA}

\author{
Murfiah Dewi Wulandari ${ }^{1)}$, Andina Widhayanti' ${ }^{2)}$, Achmad Fathoni ${ }^{3)}$, Muhammad Abduh ${ }^{4)}$, \\ Muhamad Taufik Hidayat ${ }^{5)}$
}

Fakultas Keguruan dan Ilmu Pendidikan, Univeritas Muhammadiyah Surakarta ${ }^{1}$ mdw278@ums.ac.id; ${ }^{2}$ andinawidhayanti@yahoo.co.id; ${ }^{3}$ af267@ums.ac.id;

${ }^{4}$ muhammad.abduh@ums.ac.id; ${ }^{5}$ mt.hidayat@ums.ac.id

\begin{abstract}
The purposes of this research are to 1) identify knowledge of children's personal protection from sexual abuse; 2) identifying children's personal protection skills from sexual abuse; and 3) describe efforts to prevent sexual abuse that have been carried out by the school. This type of research is descriptive qualitative research. This research was conducted at SD Muhammadiyah 1 Surakarta. The research subjects were fifth grade students. The technique of collecting data are through observation, interviews, and documentation. Qualitative data analysis techniques use the concepts conveyed by Miles and Hubermen. The validity of the data was obtained through source triangulation and technical triangulation. The results of the research indicate that 1) the child's ability to identify appropriate touch situations is good and the child's ability to identify touch situations that are not appropriate is very good. This are indicated by the child knowing that the appropriate touches such as the touch of the parents when caring for the body, the touch of doctors and nurses when examining the disease and inappropriate touches such as the touch of a housemaid or neighbor; 2) the child's knowledge and skills in reporting are very low, this are indicated by the child being unable to tell other people and children protect themselves by shouting, angry and running; 3) school prevention efforts have been carried out by schools through health education on reproduction and puberty in two stages, namely in the health and religious.
\end{abstract}

Keywords: Knowledge, Skills, Self Protection, Sexual Abuse

\section{PENDAHULUAN}

Kasus kriminal pelecehan seksual pada anak merupakan kasus yang cukup sering terjadi akhir-akhir ini. Pelecehan seksual anak adalah interaksi antara anak dan orang dewasa, setelah itu anak dipergunakan untuk menstimulasi rangsangan seksual pelaku atau orang lain yang memiliki kendali atas korban (Kelrey, 2015). UNICEF melaporkan bahwa satu dari sepuluh anak perempuan di dunia mengalami pelecehan seksual (liputan6.com, 2014). Data dari 190 negara, UNICEF mencatat bahwa anakanak di seluruh dunia secara terus menerus dilecehkan secara fisik maupun emosional mulai dari pembunuhan, tindakan seksual, bullying, dan penegakan disiplin yang terlalu 
kasar. Komisioner KPAI Jasra Putra mengungkapkan, data menunjukkan bahwa pihaknya menemukan 218 kasus kekerasan seksual anak pada tahun 2015. Sementara pada tahun 2016, KPAI mencatat terdapat 120 kasus kekerasan seksual terhadap anakanak dan di tahun 2017, tercatat sebanyak 116 kasus (kpai.go.id, 2017). Data kekerasan seksual mengalami penurunan, namun yang masih mengkhawatirkan dari laporan tersebut pelaku pelecehan adalah orang terdekat korban seperti ayah tiri dan kandung, keluarga dekat, tetangga, dan teman korban. Sedangkan data penanganan kasus pelecehan seksual anak tahun 2017 dari Pelayanan Terpadu Perempuan dan Anak Surakarta (PTPAS) Pemerintah Kota Surakarta menyebutkan adanya 18 kasus (Muzdalifah \& Wulandari, 2018).

Pelecehan seksual anak memberikan dampak negatif pada anak, baik secara fisik maupun psikis. Dampak pelecehan seksual pada anak berdasarkan hasil penelitian antara lain: anak-anak korban pelecehan seksual mengalami hambatan kesulitan attentional salah satu psikopatologi yang terkait dengan pengalaman setelah di tes dengan Post Traumatic Stress Disorder (PTSD); mengakibatkan psikopatologi pada masa dewasanya (Beach, dkk., 2013); memiliki orientasi pasangan seksual sesama jenis dan cohabitation pada saat dewasa (Wilson \& Widom, 2010); ibu yang mengalami pelecehan seksual pada masa anak-anak memiliki gangguan dalam attachment terhadap anaknya (Kwako, dkk., 2010); memiliki perasaan takut seks dan sentuhan pada saat dewasa; selain itu anak yang belum genap berusia 10 tahun, mereka menjadi trauma sampai dewasa (Suyanto, 2018).

Pelecehan seksual biasanya dilakukan oleh orang-orang terdekat anak, misalnya tetangga, paman, pembantu, dan lain-lain. Kasus pelecehan seksual yang terjadi kebanyakan adalah penganiayaan, pemerkosaan dan pencabulan dengan korban anak perempuan. Menurut KPAI 67\% kekerasan pendidikan terjadi di jenjang sekolah dasar yaitu berupa kekerasan fisik, kekerasan psikis, dan pelecehan seksual (Maradewa, 2019). Anak sekolah dasar menjadi pelaku maupun menjadi korban dari pelecehan seksual yang dilakukan temannya bahkan gurunya sendiri.

Cara paling efektif untuk mengurangi pelecehan seksual pada anak melalui program pendidikan komprehensif yang dirancang untuk melindungi anak dari pelecehan seksual (Suyanto, 2018; Topping \& Barron, 2009; Walsh, Zwi, Woolfenden, \& Shlonsky, 2015). Namun program pendidikan seks kadang terkendala dengan pendapat beberapa orang tua yang menganggap bahwa pendidikan seks untuk anak adalah tabu (Bennett, 2007; Buck \& Parrotta, 2014; Islawati \& Paramastri, 2015; Mkumbo, 2014; Naz, 2014; Paramastri \& Priyanto, 2010). Pendidikan seks tidaklah sesempit yang diekspektasikan kebanyakan masyarakat, pendidikan seks sangatlah luas. Pendidikan seks dapat menjadi bagian dari pendidikan kesehatan (Martínez, dkk., 2012). Di Norweygia, pendidikan seks untuk high school terintegrasi dalam mata pelajaran ilmu sosial, agama, biologi dan human reproduksi, sedangkan pada awal sekolah dasar belajar tentang keluarga, aturan masyarakat, norma dan peran gender, tubuh dan pubertas, hubungan dan konflik serta identitas seksual (Bartz, 2007). 
Pendidikan seks sejak dini sudah menjadi perhatian dari pemerintah Indonesia dengan memasukkan materi-materi pendidikan seks ke dalam kurikulum 2013 (K13). Dalam Peraturan Menteri Pendidikan Dan Kebudayaan No. 024 tahun 2016 tentang revisi kurikulum 2013 memuat Kompetensi Dasar (KD) yang berhubungan dengan pendidikan seks di sekolah, yaitu Pendidikan Jasmani, Olah Raga, dan Kesehatan untuk kelas satu. KD Pengetahuan berbunyi "Memahami bagian-bagian tubuh, bagian tubuh yang boleh dan tidak boleh disentuh orang lain, cara menjaga kebersihannya, dan kebersihan pakaian". Sedangkan KD Keterampilan berbunyi "Menceritakan bagianbagian tubuh, bagian tubuh yang boleh dan tidak boleh disentuh orang lain, cara menjaga kebersihannya, dan kebersihan pakaian". Dari Kompetensi Dasar tersebut, pendidikan seks masuk dalam kurikulum anak sekolah dasar. Kompetensi Dasar kelas satu dijabarkan pada tema 1 "Diriku" yang terdiri dari subtema 2 "Tubuhku" dan subtema 3 "Merawat tubuh", dalam buku siswa diharapkan siswa dapat menyebutkan anggota tubuh, bagaimana menjaga dan merawat anggota tubuh, bagian-bagian tubuh mana yang bisa dilihat orang lain dan siapa saja yang boleh melihat dan menyentuh anggota tubuhnya.

\section{METODE PENELITIAN}

Jenis penelitian ini adalah deskriptif kualitatif. Penelitian ini akan mengidentifikasi pengetahuan dan keterampilan perlindungan diri anak dari pelecehan seksual di SD Muhammadiyah 1 Surakarta. Subjek dalam penelitian ini adalah lima anak kelas V, kepala sekolah, perawat UKS, dan seorang guru kelas V SD Muhammadiyah 1 Surakarta.

Teknik pengumpulan data dalam penelitian ini adalah teknik observasi, wawancara, dan dokumentasi. Observasi dilakukan peneliti terhadap perilaku anak dalam menjaga dirinya ketika berada di lingkungan sekolah. Teknik wawancara yang digunakan dalam penelitian ini adalah teknik wawancara tidak terstruktur sehingga pedoman wawancara yang digunakan memuat garis besar permasalahan saja yang digunakan untuk memperoleh data tentang pengetahuan dan keterampilan perlindungan diri anak dari pelecehan seksual. Instrument yang digunakan peneliti mengadaptasi dari "What If" Situation Test (WIST) (Wurtele, \& Owens, 1998). Ukuran ini terdiri dari enam ilustrasi singkat, dimana tiga ilustrasi menggambarkan permintaan yang tepat untuk menyentuh (contohnya dokter akan mengobati bagian pribadimu) dan tiga ilustrasi permintaan yang tidak tepat untuk menyentuh (contohnya tetanggamu akan memfoto bagian pribadimu). WIST-III memiliki tiga skala skor, yaitu: (1) Mengenali sentuhan yang sesuai (skor 0-3); (2) Mengenali sentuhan yang tidak sesuai (skor 0-3); (3) Total skor keterampilan perlindungan diri (skor 0-24). Masing-masing keterampilannya adalah: (1) Keterampilan mengatakan (say skill) (skor 0-6); (2) Keterampilan apa yang harus dilakukan (do skill) (skor 0-6); (3) Keterampilan memberitahukan (tell skill) (skor 0-6); (4) Keterampilan melaporkan (report skill) (skor 0-6). Dari skor yang diperoleh dapat dikategorisasikan pengetahuan sentuhan yang sesuai dan tidak sesuai adalah (a) sangat baik (skor 3); (b) baik (skor 2); (c) kurang (1); 
dan (d) sangat kurang (0). Sedangkan untuk keterampilan perlindungan diri kategori (a) sangat baik (skor 6); (b) baik (skor 4-5); (c) kurang (skor 1-3); dan (d) sangat kurang (skor 0). Data yang diperoleh peneliti selanjutnya akan dianalisis dengan menggunakan konsep Miles dan Huberman meliputi reduction, data display, dan conclution. Keabsahan data penelitian diukur dengan teknik triangulasi sumber dan triangulasi metode.

\section{HASIL DAN PEMBAHASAN}

Berdasarkan identifikasi selama penelitian, pengetahuan orang yang boleh menyentuh bagian pribadinya dapat dikategorikan sangat baik. Semua subjek membolehkan orang tua, dokter dan perawat menyentuh bagian pribadinya. Namun ada tiga subjek yang menyatakan membolehkan dengan pengecualian. Seperti yang diungkapkan oleh subjek satu (perempuan):

"Kalau dokternya perempuan boleh tapi kalau laki-laki tergantung, kalau sudah tua tidak terlalu malu."

Sedangkan subjek dua (laki-laki) mengungkapkan:

"Kalau dokternya cewek tidak boleh."

Pengetahuan anak tentang identifikasi orang yang tidak boleh menyentuh bagian pribadi masuk dalam kategori baik. Empat dari lima subjek menyatakan orang yang tidak boleh menyentuh bagian pribadi yaitu, orang terdekat seperti pengasuh, paman/bibi, kakek/nenek; tetangga; dan orang asing yang tidak dikenal. Penelitian yang sama dilakukan Zhang dkk.(2013) di Cina dan Kenny dkk.(2012) di AS dengan pengetahuan sentuhan yang sesuai dan sentuhan yang tidak sesuai sebagian besar baik.

Keterampilan perlindungan diri anak dari pelecehan seksual dapat dilihat dari bagaimana anak bersikap dan berkata. Anak mampu menolak dengan baik secara verbal, menghindar keluar dari situasi-situasi yang membahayakan, memberitahu dan melaporkan kepada orang lain. Keterampilan menolak tindakan pelecehan seksual secara verbal dapat dikatakan sangat baik, dengan berkata "tolong", berkata "tidak mau", dan berkata "jangan pegang kemaluanku". Seperti yang diungkapkan subjek dua (laki-laki):

"Tidak boleh, tidak boleh memperlihatkannya karena aurat."

Keterampilan menolak tindakan pelecehan seksual dengan perilaku dilakukan dengan sangat baik, dengan berteriak, lari, dan menggigit pelaku. Seperti yang diungkapkan subjek ketiga (perempuan):

"Teriak dan lari."

Keterampilan memberitahukan tindakan pelecehan seksual pada orang lain masuk kategori kurang baik, ada beberapa subjek yang tidak memberitahukan pada orang lain dan hanya sedikit subjek yang memberitahukan pada orang lain. Meskipun ada jawaban subjek yang akan memberitahukan pada orang tuanya namun mereka kesulitan untuk melaporkan peristiwa pelecehan seksual. Seperti yang diungkapkan subjek keempat (perempuan): 
"Tidak, nanti kalau dikasih tau nanti diejek, tidak memberitahu orangtua juga nanti takut dimarahin."

Hasil penelitian keterampilan perlindungan diri anak di beberapa negara juga masih kurang baik dalam hal melaporkan kepada orang lain (Kenny dkk., 2012; Sarno, Julie \& Wurtele, 1997; Zhang dkk., 2013).

Program yang dilaksanakan SD Muhammadiyah 1 Surakarta untuk melaksanakan upaya pencegahan pelecehan seksual sehingga anak dapat melindungi dirinya adalah dengan melaksankan penyuluhan kesehatan tentang reproduksi dan pubertas. Anak mempunyai kesadaran untuk tertib diri yaitu menggunakan double celana, memakai baju yang tidak ketat dan memakai kerudung yang besar. Sejauh ini program tersebut berhasil karena tidak ada laporan kasus pelecehan seksual anak di sekolah. Keunggulan program upaya pencegahan ini yaitu diadakan selama dua tahap yang mengkaji dari dua bidang yang berbeda dan sama-sama penting. Kegiatan dilakukan diawali dengan muatan materi bidang agama, sehingga anak yang baligh mengetahui apa saja yang harus dilakukan. Kegiatan selanjutnya muatan bidang ilmiah atau kesehatan, anak mengetahui apa saja yang harus dilakukan ketika memasuki masa pubertas. Seperti yang diungkapkan kepala sekolah berikut ini:

"Program pencegahan pelecehan seksual diantaranya seminar reproduksi anak kelas VI dan sosialisasi kelas V untuk anak yang mulai menstruasi dan mimpi basah, dipandang dari segi kesehatan sampai dengan segi agama, mulai bagaimana mereka merawat dirinya ketika mendapatkan mentruasi dan apa yang harus dilakukan, begitu juga untuk anak-laki-laki ketika mendapatkan mimpi basah, kemudian dijelaskan juga efek-efek atau akibat apa yang akan muncul setelah mendapatkan menstruasinyakalau perempuan pasti akan disampaikan bahwa yang mendapatkan menstruasi sudah bisa hamil (atau dibuahi) sedangkan yang laki-laki yang sudah mimpi basah dipastikan dapat membuat hamil (membuahi)."

Hasil tersebut sama dengan penelitian yang dilakukan oleh Alicia Hutardo (2014). Pada penelitian tersebut Alicia mengajak anak-anak untuk mengunjungi museum di El Savador. Metode yang dilakukan yang digunakan adalah bermain dan belajar dengan pemandu yang profesional. Hal ini efektif untuk memberikan pengetahuan tentang pelecehan seksual kepada anak. Anak diberi pertanyaan sebelum memasuki museum dan setelah keluar dari museum. Hasilnya adalah nilai anak mengalamai peningkatan.

\section{SIMPULAN}

Pengetahuan yang sudah dimiliki anak adalah mengenai perlindungan diri dari pelecehan seksual yaitu mengenali dan menyadari adanya sentuhan yang tepat dan tidak tepat yang dilakukan oleh orang lain, mengetahui bagian tubuh pribadi yang boleh dan tidak boleh disentuh oleh orang lain. Keterampilan yang dimiliki anak mengenai perlindungan diri dari pelecehan seksual yaitu dengan mampu mengenali, menolak, dan melaporkan tindak pelecehan seksual. Anak mampu berkata dan bersikap tentang tindakan pelecehan seksual. Upaya pencegahan pelecehan seksual anak yang dilakukan 
oleh sekolah untuk langkah perlindungan diri yaitu dengan penyuluhan kesehatan tentang reproduksi dan pubertas. Keberhasilan program tersebut ditandai dengan tidak adanya laporan tentang kasus pelecehan seksual anak di SD Muhammadiyah 1 Surakarta.

\section{DAFTAR PUSTAKA}

Abduh, Muhammad dan Wulandari D. Murfiah. (2016). Model Pendidikan Seks pada Anak Sekolah Dasar Berbasis Teori Perkembangan Anak. The Progressive and Fun Education Seminar. ISBN: 978-602-361-045-7 403-411

Akbar, Zalina dkk. (2014). Program Pendidikan Seks untuk Meningkatkan Proteksi Diri dari Eksploitasi Seksual pada Anak Usia Dini. Jurnal Parameter Vol 25 No. 2 doi: org10.21009/parameter252.07

Alicia Hurtado, MD. (2014). Children's Knowledge of Sexual Abuse Prevention in El Salvador. Icahn School of Medicine at Mount Sinai: Annals of Global Health

Bartz, T. (2007). Sex education in multicultural Norway. Sex Education, 7(1), 17-33. https://doi.org/http://dx.doi.org/10.1080/14681810601134702

Beach, S. R. H., Brody, G. H., Lei, M. K., Gibbons, F. X., Gerrard, M., Simons, R. L., ... Philibert, R. a. (2013). Impact of child sex abuse on adult psychopathology: A genetically and epigenetically informed investigation. Journal of Family Psychology, 27(1), 3-11. https://doi.org/10.1037/a0031459

Bennett, L. R. (2007). Zina and the enigma of sex education for Indonesian Muslim youth. Sex Education, 7(4), 371-386. https://doi.org/10.1080/14681810701635970

Bily. (2019). Tahun Lalu Kekerasan Seksual Dominasi Kasus Anak yang Berhadapan $\begin{array}{lllll}\text { dengan Hukum. } & \text { Diakses pada } & \end{array}$ http://www.tribunnews.com/nasional/2019/01/09/tahun-lalu-kekerasan-seksualdominasi-kasus-anak-yang-berhadapan-dengan-hukum.

Buck, A., \& Parrotta, K. (2014). Students teach sex education: introducing alternative conceptions of sexuality. Sex Education, 14(1), 67-80. https://doi.org/10.1080/14681811.2013.830968

Darmadi, Hamid. (2013). Metode Penelitian Pendidikan dan Sosial. Bandung: Alfabeta Esya Anesty, Mashudi. (2015). Pencegahan Kekerasan Seksual Pada Anak Melalui Pengajaran Personal Safety Skills. Jurnal Metode Didaktik

Islawati, I., \& Paramastri, I. (2015). Program "Jari Peri" sebagai Pelindung Anak dari Kekerasan Seksual. Jurnal Psikologi, 42, No. 2(2), 115-128.

Kenny, C. Maureen. Dan R., Reena. (2008). Child Sexual Abuse: From Prevention to Self-Protection. Wiley InterScience: 36-54: DOI: 10.1002/car.1012 
Kerley, Dina SR. (2015). Hubungan Karakteristik Orang Tua dengan Pengetahuan Orang Tua tentang Kekerasan Seksual pada Anak Usia Prasekolah di Kelurahan Grogol Selatan Kebayoran Lama Jakarta Selatan. Skripsi, FKIP. Universitas Islam Negeri Syarif Hidayatullah.

Kenny, M. C., Wurtele, S. K., Alonso, L., Kenny, M. C., Wurtele, S. K., \& Evaluation, L. A. (2012). Evaluation of a Personal Safety Program with Latino Preschoolers Evaluation of a Personal Safety Program with Latino Preschoolers, 8712(October). https://doi.org/10.1080/10538712.2012.675426

Kwako, L. E., Noll, J. G., Putnam, F. W., \& Trickett, P. K. (2010). Childhood sexual abuse and attachment: An intergenerational perspective. Clinical Child Psychology and Psychiatry, 15(3), 407-422. https://doi.org/10.1177/1359104510367590

Maradewa, Rega. (2019). "KPAI: 67 Persen Kekerasan Bidang Pendidikan Terjadi di Jenjang SD” Diakses pada 19 Juli 2019 http://www.kpai.go.id/berita/kpai-67-persen-kekerasanbidang-pendidikan-terjadi-di-jenjang-sd

Martínez L., J., Carcedo J., R., Fuertes, A., Vicario-Molina, I., Fernández-Fuertes A., A., Orgaz, B., ... Fernández-Fuertes A., A. (2012). Sex education in Spain: teachers' views of obstacles. Sex Education, 12(4), 425-436. https://doi.org/10.1080/14681811.2012.691876

Mkumbo, K. a. (2014). Students' attitudes towards school-based sex and relationships education in Tanzania. Health Education Journal, 73(6), 642-656. https://doi.org/10.1177/0017896913510426

Muzdalifah, R. A., \& Wulandari, M. D. (2018). Upaya Pencegahan Kekerasan Seksual Terhadap Anak Oleh Pelayanan Terpadu Perempuan Dan Anak Surakarta (PTPAS) Di Kota Surakarta. Evolution, 1-14.

Naz, R. (2014). Sex Education in Fiji, 664-687. https://doi.org/10.1007/s12119-0139204-3

Paramastri, I., \& Priyanto, M. A. (2010). Early Prevention Toward Sexual Abuse on Children, 37(1), 1-12.

Sarno, Julie \& Wurtele, S. (1997). Effects of a personal safety program on preschoolers' knowledge, skill, and perceptions of child sexsual abuse. Child Maltreatment, 2.

Suyanto, B. (2018). Problem Pendidikan dan Anak Korban Tindak Kekerasan. Yogyakarta: Suluh Media.

Topping, K., \& Barron, I. (2009). School-based child sexual abuse prevention programmes: A review of effectiveness, 79(1), 431-463. https://doi.org/10.3102/0034654308325582

Walsh, K., Zwi, K., Woolfenden, S., \& Shlonsky, A. (2015). School-Based Education 
Programs for the Prevention of Child Sexual Abuse: A Cochrane Systematic Review and Meta-Analysis. Research on Social Work Practice, 1-23. https://doi.org/10.1177/1049731515619705

Wilson, H. W., \& Widom, C. S. (2010). Does physical abuse, sexual abuse, or neglect in childhood increase the likelihood of same-sex sexual relationships and cohabitation? A prospective 30-year follow-up. Archives of Sexual Behavior, $39(1), 63-74$.

Wurtele, S.K., Hughes, J. \& Owens, J. S. (1998). An Examination of the Reliability of the "What If" Situations Test: A Brief Report. Child Sexual Abuse.

Zhang, W., Chen, J., Feng, Y., Li, J., Zhao, X., \& Luo, X. (2013). Young children's knowledge and skills related to sexual abuse prevention: A pilot study in Beijing, China. Child Abuse \& Neglect. https://doi.org/10.1016/j.chiabu.2013.04.018 